Norbert Molina Medina*

\title{
Los orígenes de la presencia diplomática venezolana en China: El Consulado General en Shanghai (1936-1938)
}

\section{The Origins of the Venezuelan Diplomatic Presence in China: The Consulate General in Shanghai (1936-1938)}

https://doi.org/10.1515/sai-2021-2003

Publicado en línea septiembre 2, 2021

Resumen: A finales de agosto de 1941, fue designado Li Dijun (李迪俊) como el primer Enviado Extraordinario y Ministro Plenipotenciario de China en Venezuela. Li, arribó a Caracas a inicios de 1943 y presentó formalmente sus Cartas Credenciales al presidente Isaías Medina Angarita (1941-1945) el 13 de abril. Asimismo, instaló la Legación de China en la capital del país caribeño, quedando formalizadas de esta manera las relaciones binacionales. Ahora bien, previo a este importante hecho histórico, existe un antecedente no menos trascendente que obedece a la creación de una efímera sede consular venezolana en la ciudad de Shanghai en 1936, para la cual fue designado como Cónsul General, el 22 de julio, el poeta y escritor José Miguel Ferrer. En tal sentido, nuestro objetivo es, a través del método históricodocumental, analizar los orígenes de la presencia diplomática venezolana en China, a través de lo que fue la referida sede consular entre 1936 y 1938.

Palabras clave: Venezuela, China, relaciones diplomáticas, Consulado General en Shanghai

Este trabajo constituye un adelanto de la investigación para la tesis doctoral Historia de las relaciones diplomáticas Venezuela - China (1943-2018), que se desarrolla en el Doctorado en Estudios Políticos, Facultad de Ciencias Jurídicas y Políticas, Universidad de Los Andes, Mérida Venezuela.

*Corresponding author: Norbert Molina Medina, Center for African and Asian Studies, University of Los Andes (ULA), Mérida, Venezuela, E-mail: norbertmolinamedina@gmail.com 
Abstract: At the end of August 1941, Li Dijun (李迪俊) was appointed as the first Chinese Envoy Extraordinary and Minister Plenipotentiary to Venezuela. Li arrived in Caracas in early 1943 and formally presented his Credentials to President Isaías Medina Angarita (1941-1945) on April 13. Likewise, he installed the Chinese Legation in the capital of the Caribbean country, thus formalizing binational relations. However, prior to this important historical event, there was a no less transcendent antecedent due to the creation of an ephemeral Venezuelan consular headquarters in the city of Shanghai in 1936, for which the poet and writer José Miguel Ferrer was appointed Consul General on July 22. In this sense, our objective is, through the historical-documentary method, to analyze the origins of the Venezuelan diplomatic presence in China, focusing on consular headquarters between 1936 and 1938.

Keywords: Venezuela, China, diplomatic relations, consulate general in Shanghai

\section{Introducción}

En el discurso oficial sino-venezolano de las últimas décadas del siglo XX y sobre todo las dos primeras del XXI, se argumenta que los vínculos diplomáticos entre Venezuela y China datan del 28 de junio de 1974. Esto último nos llevaría a pensar que en 2020 fueron conmemorados 46 años de los mismos. Sin embargo, investigaciones académicas dan cuenta que estos dos países iniciaron sus relaciones diplomáticas mucho antes de lo que parece. Para finales de agosto de 1941, fue designado Li Dijun (李迪俊) como Enviado Extraordinario y Ministro Plenipotenciario de China en Venezuela, el cual arribó a la Caracas iniciando 1943 con la misión primera de acreditarse ante el presidente Isaías Medina Angarita (13 de abril de 1943), para luego proceder a instalar la Legación de China en la capital venezolana, y con ello, dejar formalmente establecidas las relaciones binacionales (Molina Medina 2016, p. 70).

Lo que ocurrió en junio de 1974, luego que la República Popular China recuperara su asiento en la Organización de las Naciones Unidas (ONU) en octubre de 1971, es que la gran mayoría de los países latinoamericanos rompieron sus relaciones con Taiwán, hasta entonces el representante chino en la ONU, y normalizaron sus relaciones con el legítimo representante en suelo continental (Molina Medina 2015). De tal manera que para 1974 ya habían pasado 31 años desde la acreditación del primer diplomático chino en Caracas y de la creación de la oficina de representación de su Gobierno en la capital de la nación caribeña. Ahora bien, previo a este importante hecho histórico en las relaciones binacionales, existe un antecedente no menos trascendente que obedece a la instalación de una efímera sede 
consular venezolana en la ciudad de Shanghai en 1936, para la cual fue designado como Cónsul General, el 22 de julio, el poeta y escritor José Miguel Ferrer.

En ese sentido, a través del método histórico-documental, el objetivo de nuestra contribución es analizar los orígenes de la presencia diplomática venezolana en China, a través de lo que fue la referida sede consular entre 1936 y 1938. Para ello, hemos utilizado un conjunto de fuentes documentales resguardadas en el Archivo Histórico del Ministerio del Poder Popular para Relaciones Exteriores de Venezuela (en adelante AHMPPRE: secciones Consulado; Política; y Administración y Servicio Consular), así como la Gaceta Oficial de los Estados Unidos de Venezuela que corresponden al período objeto de estudio. De igual manera, otras de carácter bibliohemerográfico especializadas que nos han ayudado a dar el soporte necesario a las afirmaciones realizadas.

\section{El origen del Consulado General de Venezuela en Shanghai}

La posibilidad de apertura de un consulado venezolano en la República China se remonta por lo menos a finales de la década de los años veinte del siglo pasado. Desde Hong Kong, el 5 de junio de 1929, M. del Pan, dueño de la firma comercial M. del Pan \& Co. Import - Export and Manufacturers representatives, se dirigió al Canciller Pedro Itriago Chacín, con la finalidad de solicitar la representación de Venezuela en la colonia inglesa de Hong Kong: "gustoso tendría el alto honor de hacerme cargo de esta responsabilidad si Su Excelencia tiene a bien nombrarme Cónsul de la República de Venezuela en Hong Kong, China”.

Sobre este asunto, Itriago Chacín ofició el 26 de julio a Diógenes Escalante, representante diplomático de Venezuela en Londres para que indagara la conveniencia de una posible designación, establecer un consulado ad honorem en Hong Kong y nombrar para el mismo, a M. del Pan. En respuesta, el Encargado de Negocios en Gran Bretaña, Arroyo Lameda, informó el 5 de septiembre a Itriago Chacín, que dada la importancia mercantil de Hong Kong, la creación de un consulado podría ser a la larga beneficioso para el comercio venezolano, y que por tanto dicha medida era para la Legación en Londres aconsejable, sin embargo, como paso previo creía conveniente solicitar referencias de una de las cámaras de comercio de aquel puerto sobre M. del Pan (AHMPPRE 1929a, Consulados (China), Expediente s. n.). ${ }^{1}$

1 Véanse las correspondencias: s. n., Hong Kong 5 de junio de 1929 (p. 1); № 1.043, Caracas 26 de julio de 1929 (p. 1); y N²58, Londres 5 de septiembre de 1929 (p. 1). 
M. del Pan se dirigió a Arroyo Lameda el 4 de noviembre, expresando no poder complacer a la solicitud de referencia personal por parte de la Cámara de Comercio de Hong Kong, ya que se había negado a formar parte de la misma desde hacía más de cinco años y recalcó que su firma era española, la cual compartía con firmas americanas, francesas, italianas y alemanas, que no pertenecían a la cámara de comercio de la colonia inglesa. Por tal razón, retiró su solicitud: "pues no quiero ser motivo de que su Gobierno se demore en nombrar a otro que pueda velar por la prosperidad de Venezuela ... ”. Días después, el 11 de diciembre, Diógenes Escalante le escribió al ministro Itriago Chacín para dar cuenta que M. del Pan no había podido obtener el requisito solicitado, ni tampoco otro equivalente, considerando como un asunto importante pensar en otro candidato, si también ese era el parecer del Canciller (AHMPPRE 1929a, Consulados (China), Expediente s. n.). ${ }^{2}$

Otro caso similar tuvo lugar cuando igualmente desde Hong Kong, el 25 de noviembre, Julane Tong envió nota a Itriago Chacín para solicitar su nombramiento como Cónsul de Venezuela en ese territorio, para "poder establecer relaciones estrechas de amistad entre la China y Venezuela”. De nuevo, el Canciller acudió a la representación diplomática en Londres, el 15 de enero de 1930, remitiendo la propuesta de Julane Tong y requiriendo se informaran con el diplomático chino en Gran Bretaña sobre la conducta, posición y demás datos del mencionado solicitante (AHMPPRE 1929b, Consulados (China), Expediente $\mathrm{N}^{\circ} 2$ ). ${ }^{3}$

Desde Londres, Diógenes Escalante el 21 de julio de 1930, indicó que del informe remitido por la Legación de China concluía que Julane Tong "no parecía en verdad el indicado para el desempeño de dicho Consulado". Además agregó que de la información recibida se desprendía que el señor Tong era una persona de buena conducta, pero que conocía poco el idioma inglés, carecía de preparación consular y no tenía buena posición financiera, dado que había perdido sus haberes económicos en especulaciones mercantiles (AHMPPRE 1929b, Consulados (China), Expediente $\mathrm{N}^{\circ}$ 2). ${ }^{4}$ Así, quedaron frustradas las primeras iniciativas particulares de apertura de un consulado en Hong Kong.

Sin embargo, pocos años después, en 1936, el Gobierno de Eleazar López Contreras (1935-1941) decidió crear el Consulado General de los Estados Unidos de Venezuela en China (Ministerio de Relaciones Exteriores (en adelante MRE) 1937, p. 503; Molina Medina 2016, p. 70), ${ }^{5}$ con residencia en Shanghai, designando a José

2 Véanse las notas s. n., Hong Kong 4 de noviembre de 1929 (p. 1); y N 336, Londres 11 de diciembre de 1929 (p. 1).

3 Véanse las notas s. n., Hong Kong 25 de noviembre de 1929 (pp. 1-2); y ํ71, Caracas 15 de enero de 1930 (p. 1).

4 Véase la nota $\mathrm{N}^{\circ} 232$, Londres 21 de julio de 1930 (p. 1).

5 El Consulado General de Venezuela en Shanghai (en el este de China, centrada en la costa del mar de China oriental) fue instalado en Cathay Mansions, Rues Cardinal Mercier y Bourgeat. 
Miguel Ferrer como Cónsul General en el país asiático (Centro de Investigaciones Literarias 1974, p. 293; Vanegas 1990, pp. 81-82), ${ }^{6}$ el 22 de julio de ese mismo año (Ministerio de Relaciones Interiores 1936, p. 108.939). La instalación se llevó a cabo en la mencionada ciudad para el mes de octubre, iniciando así una primera etapa de acercamiento con esa nación, la cual muy rápidamente habría de verse condicionada por la guerra desatada en China desde 1937.

\section{Los avatares de la guerra}

Entre 1937 y 1945, China fue invadida por Japón. El asalto a Nanjing en 1937 obligó al Gobierno nacional del Partido del Guomindang a mudar su capital a Chongqing. A partir de ese momento se formó el segundo frente unido entre guomindangistas y los comunistas contra el invasor japonés (Cornejo Bustamante 2006, p. 459). Podría decirse entonces, que durante esta primera etapa de presencia consular venezolana en Shanghai (1936-1938) representó para el poeta Ferrer un cúmulo de experiencias difíciles y de mucha actividad (Molina Medina 2016, p. 71 ), ${ }^{7}$ tal y como puede apreciarse en cada una de sus correspondencias. Otra distinta, da cuenta de intereses manifiestos como la comunicación dirigida a José Miguel Ferrer desde Caracas el 19 de julio de 1937, por parte de Abraham Capriles, quien, entre otras cosas, le pide: "Mucho agradezco su promesa de no dejar de mano su valiosa recomendación para mi nombramiento de Cónsul General ad honorem de China en Venezuela, con residencia en Caracas. Esa nación necesita aquí un representante que expida pasaportes, que vele por sus hijos y defienda sus intereses ...". Sobre este particular, no encontramos más ninguna otra referencia. (AHMPPRE 1937-1938, Consulados (China), Legajo $\left.\mathrm{N}^{\circ} 3\right) .^{8}$

6 El poeta José Miguel Ferrer (1903-1969), nació en Caracas el 20 de julio de 1903. Fue colaborador de varios periódicos: Fantoches (Caracas), El Impulso (Barquisimeto) y El Heraldo (Caracas); Miembro fundador del grupo literario "Viernes"; Fundador y secretario del "Pen Club" en Venezuela. Miembro de la Asociación de Escritores Venezolanos, donde desempeñó cargos de dirección; Contabilista; Funcionario diplomático en China. Divulgó en español la poesía antigua, clásica y contemporánea de China.

7 En el artículo de nuestra autoría sobre las entre relaciones Venezuela-China (1943-1974), inicialmente habíamos dicho que la presencia de José Miguel Ferrer en China se había extendido hasta 1943, dado un dato que conseguimos en el Libro Amarillo 1998 (MRE 1999, p. 622), cuando se planteó un proyecto de investigación sobre la labor de José Miguel Ferrer en China y de Carlos Rodríguez Jiménez en Japón. Sin embargo, una vez revisada la documentación oficial pertinente, nos percatamos que la primera etapa del Consulado General de Venezuela en Shanghai, y por ende la de José Miguel Ferrer, duró hasta julio de 1938.

8 Véase la nota s. n., Caracas 19 de julio de 1937 (p. 1). 
Ya en funciones, José Miguel Ferrer debió afrontar las dificultades de un país en medio de disputas no resueltas desde su surgimiento como república. El movimiento republicano chino que implosionó en 1911 fue ideológica y socialmente heterogéneo, aglutinando a todos aquellos sectores sociales que por diversas razones estaban descontentos con el régimen feudal, sobre todo, por la situación de dominación y sometimiento que llevaron a cabo las potencias extranjeras. Sostiene el historiador Romer Cornejo Bustamante, que detrás de ese movimiento no había ni organización política ni un programa de gobierno coherente, siendo fácil para los sectores conservadores, después de caída la última dinastía, apropiarse del poder político e intentar reproducir la misma situación contra la cual habían conspirado (Cornejo Bustamante 1996, pp. 335-351).

El 1 de diciembre de 1936, Ferrer escribió al Ministro de Relaciones Exteriores, Esteban Gil Borges, para dar cuenta que el Gobierno de Nanjing (AHMPPRE 19371938, Consulados (China), Legajo $\left.\mathrm{N}^{\circ} 3\right)^{9}$ había informado al Consulado venezolano que, a partir del 1 de enero de 1937, la pena de muerte sería aplicada a todos los ciudadanos chinos que fabricaran, vendieran o consumieran estupefacientes (AHMPPRE 1937, Política (China), Expediente $\left.\mathrm{N}^{\circ} 342\right) .{ }^{10}$ Tal medida se explica por lo ocurrido en China durante la época de humillaciones imperialistas (denominado así por su historiografía) en el siglo XIX. A partir de 1800, se incrementó el comercio ilegal del opio en China, usado por los europeos para balancear su comercio con el país asiático. Ante los intentos de poner fin a esta situación, los europeos reaccionaron con la guerra. Durante la Primera Guerra del Opio (1839-1842), China se vio obligada a abrir cinco puertos al comercio y a ceder a Hong Kong. En 1842, Gran Bretaña la obliga a firmar el Tratado de Nanjing (1842), el primero de una serie de tratados desiguales. Con la Segunda Guerra del Opio (1856-1860), nuevas acciones bélicas arremetieron contra China, forzando la apertura de otros seis puertos, la residencia de diplomáticos occidentales en Beijing y la firma del Tratado de Tianjin (1858), entre otros aspectos (Anguiano Roch 2010, pp. 232-243).

Días después, el 10 de diciembre, nuevamente acudió al Canciller para consultar sobre una invitación que recibió para que Venezuela formara parte de la Corporación Consular de Shanghai, en donde estaban agrupados los funcionarios

\footnotetext{
9 Nanjing fue capital de China desde 1928 hasta 1937. El 8 de diciembre de 1937, José Miguel Ferrer ofició al Canciller Esteban Gil Borges, para informar de que había sido notificado por el Ministerio de Relaciones Exteriores del Gobierno chino que, debido a medidas de emergencia, debió trasladar la capital de la república de Nanjing a Hankow (o Hankou, fue una de las tres ciudades, las otras dos fueron Wuchang y Hanyang, cuya fusión dio origen a la actual ciudad de Wuhan, capital de la provincia de Hubei, China), ubicada en la región sur-este de China. Véase la nota ${ }^{\circ} 79$, Shanghai 8 de diciembre de 1937 (p. 1).

10 Véase la nota $\mathrm{N}^{\circ}$ 16, Shanghai 1 de diciembre de 1937 (p.1). "Suspensión del tráfico de estupefacientes".
} 
diplomáticos de todos los países con un carácter de autoridad dentro del territorio chino, recomendando además su ingreso por los beneficios que, en materia de “prestigio, propaganda y promoción comercial” podían obtenerse. Desde Caracas se respondió con la solicitud de que fueran remitidos, a la mayor brevedad, los requisitos y documentos oficiales necesarios. Sobre este aspecto, no encontramos en la documentación revisada indicio alguno de si Venezuela ingresó o no a la mencionada organización (AHMPPRE 1936, Consulados (China), Expediente $\mathrm{N}^{\circ} 1$ ). ${ }^{11}$

Con la llegada de la guerra en 1937 la situación cambió drásticamente. El 15 de agosto, José Miguel Ferrer se dirigió a la Cancillería para notificar de las dificultades que estaba enfrentando, refiriendo que el Consulado se encontraba en la concesión francesa, el cual junto al Shanghai Municipal Council, habían declarado estado de alarma. También, destacó que el Gobierno chino les había comunicado la gravedad del asunto a fin de prever medidas pertinentes. En caso de evacuación, las oficinas del Consulado quedarían bajo vigilancia y atención del ciudadano canadiense J. M. Wilfrid Beaudry, persona de confianza quien desde su llegada le había servido como intérprete y secretario. Ferrer daba cuenta en sus comunicaciones que Shanghai carecía de servicio de gas, tranvías, taxis, entre otros. También, que se había suspendido la venta de gasolina, supliéndose apenas cinco galones cada dos días a los consulados o legaciones. (AHMPPRE 1937, Política (China), Expediente $\left.\mathrm{N}^{\circ} 345\right) .^{12}$

El Cónsul General venezolano hubo de trasladarse a Manila, isla de Filipinas, luego de haber obtenido el permiso del Ministerio de Relaciones Exteriores venezolano a finales de agosto de 1937. (AHMPPRE 1938, Consulados (China), Expediente s. n.). ${ }^{13}$ Así lo hizo saber al Ministro Gil Borges el 3 de septiembre, contando sobre su llegada el día anterior y aclarando no haber optado por Hong Kong dada la epidemia de cólera-morbo, que según al parecer estaba controlada por las autoridades sanitarias. Para los asuntos de carácter oficial, dejó encargado al Cónsul General de Brasil, quien gozaba de derechos de extraterritorialidad. Sobre la prolongación de la guerra, de extenderse por un mes más, consideraba conveniente trasladar el Consulado a los alrededores de Hong Kong, en territorio chino.

En los días sucesivos, la correspondencia del funcionario venezolano estuvo centrada en solicitar instrucciones que autorizaran el traslado provisional del Consulado a Hong Kong. El 7 de octubre dio cuenta al Canciller de haberlas recibido finalmente, a través del Cónsul en Manila (AHMPPRE 1937, Consulados

11 Véanse las notas $\mathrm{N}^{\circ} 30$, Shanghai 10 de diciembre de 1936 (p. 1) y $\mathrm{N}^{\circ} 394$, Caracas 21 de enero de 1937 (p. 1).

12 Véase la nota $\mathrm{N}^{\circ} 65$, Shanghai 15 de agosto de 1937 (p. 1).

13 Véase la nota $\mathrm{N}^{\circ}$ 9, Shanghai 1 de febrero de 1938 (p. 4). 
(China), Expediente $\mathrm{N}^{\circ}$ 2), ${ }^{14} \mathrm{y}$ así marcharse hasta Shanghai -lo que hizo el 18 de octubre-, vía Hong Kong, con el propósito de recuperar el archivo y demás pertenencias de la oficina consular y regresarse a esta última, en donde actuaría temporalmente, siendo una de sus primeras gestiones la atención de algunas venezolanas residentes de esa ciudad (AHMPPRE 1937-1938, Consulados (China), Legajo $\mathrm{N}^{\circ}$ 3). ${ }^{15}$ Por las comunicaciones revisadas, eso no pareció ocurrir. Ya en Shanghai anunció esperar la primera ocasión que los riesgos de la guerra le permitiesen, para poder viajar a Hong Kong, dejando solo los muebles de la oficina y a un encargado para la recepción de correspondencia -la cual sería enviada a Hong Kong-, además del Consulado de Brasil como representante en los asuntos relacionados con Venezuela en ese puerto. Subrayaba José Miguel Ferrer:

Personalmente, Señor Ministro, tengo que deplorar el entorpecimiento sufrido a causa de la guerra en cuanto a mi labor de intercambio comercial entre Venezuela y China, el cual si un poco difícil a causa de la distancia y sistemas de negocios, nunca imposible desde el punto de vista de la asistencia comercial necesaria entre países modernos y de los deberes que atañen a los representantes de Venezuela en el exterior (AHMPPRE 1938, Consulados (China), Expediente s. n.). ${ }^{16}$

También dio cuenta, en noviembre de 1937, de los estragos de la ocupación japonesa, lo que afectó a las concesiones extranjeras dado el cerco fluvial y terrestre, y en donde: "Prácticamente no existe ninguna autoridad civil ni militar China en Shanghai". ${ }^{17}$ Del epistolario producido por Ferrer en aquellos meses sucesivos a su regreso a Shanghai, puede construirse una idea de los avatares que vivió este primer funcionario consular venezolano y de la realidad que enfrentaba China para la época. A finales de noviembre de 1937, acudió de nuevo al Canciller para notificar el contenido de la nota entregada el 22 de noviembre, por el Cónsul General del Japón, en donde estaban contenidas las condiciones que debían cumplir las autoridades de la concesión internacional y la concesión francesa: a) Supresión de toda publicación anti japonesa, eliminación de todos los departamentos del Guomindang, restricción

14 También de esta fecha es la comunicación emitida por Ferrer desde Manila al Canciller Gil Borges para informar del bombardeo sobre Shanghai, y en la que afirmó haber recibido noticias de la explosión de una pequeña bomba frente al edificio donde estaban instaladas las oficinas del Consulado General de Venezuela ( $\mathrm{N}^{\circ} 246$, Reute Vallón, segundo piso), sin mayores daños causados. Véase la nota s. n., Manila 7 de octubre de 1937 (p. 1).

15 Véanse las notas s. n., Manila 3 de septiembre de 1937 (p. 1); nota s. n., Manila 9 de septiembre de 1937 (p. 1); nota s. n., Manila 5 de octubre de 1937 (p. 1) y nota s. n., Manila 7 de octubre de 1937 (p. 1).

16 Véase la nota s. n., Shanghai 23 de octubre de 1937 (pp. 1-2). "El Cónsul informa del traslado de la oficina de Shanghai".

17 Véase la nota $\mathrm{N}^{\circ}$ 71, Shanghai 15 de noviembre de 1937 (p. 1) (AHMPPRE 1937, Política (China), Expediente $\mathrm{N}^{\circ} 343$ ). 
a la propagación de carteles anónimos y de cualquier literatura, radiodifusión, películas anti japonesa, e igualmente "la presente manía de espionaje y de caza de traidores a la causa China”; b) Supresión de todos los órganos representativos chinos, tanto centrales como locales, y la supervisión efectiva de las actividades de los jefes del Gobierno chino y de los partidos políticos; c) Prohibición de la censura China sobre comunicaciones postales y telegráficas; d) Prohibición de la censura China sobre prensa y agencias de noticias para el exterior; y e) Supresión de comunicaciones inalámbricas chinas que no sean debidamente autorizadas. Sobre estos aspectos, las autoridades de las concesiones respondieron a sus homólogas japonesas que actuarían hasta donde fuera posible, "siempre y cuando no se quebrantaran sus derechos de extraterritorialidad” (AHMPPRE 1937, Política (China), Expediente $\mathrm{N}^{\circ}$ 345). ${ }^{18}$

A pesar de la guerra, el Cónsul venezolano debió atender otros temas que demandaban de su servicio. Uno de ellos parece haber sido el interés mutuo, junto al Cónsul General de Venezuela en Tokio, Carlos Rodríguez Jiménez, por la designación de un funcionario diplomático de mayor rango tanto en China como en Japón. ${ }^{19}$ Sobre el particular desde Tokio, el 27 de noviembre de 1937, Rodríguez Jiménez le escribió:

Yo escribí también hace pocos días sobre la conveniencia y necesidad de que haya aquí un representante diplomático, y sugerí que se combinase el Cónsul General con el cargo de Encargado de Negocios; creo conveniente que vuelvas tú a escribir sobre lo mismo con relación a China; así seremos dos machacando sobre ese tema y quizás si logremos algo en beneficio del país con una mayor amplitud de nuestras atribuciones, y también algo beneficioso para nosotros mismos, por el mayor ambiente y estímulo que se nos dé con un pequeño ascenso. Yo estoy seguro de que si el Dr. Gil Borges pudiera organizar la carrera consular y diplomática en forma racional, y moderna, lo haría, pero seguramente el Congreso no acepta esos métodos tan modernos (AHMPPRE 1937, Consulados (China), Expediente $\left.\mathrm{N}^{\circ} 4\right){ }^{20}$

Otro de los asuntos tratados, no menos importante, fueron las medidas sanitarias que debían tomarse sobre los productos chinos. El 1 de diciembre de 1937, comunicó a Caracas que dada la situación anormal predominante en los puertos chinos, se hacía impracticable cualquier supervisión o ejercicio de medidas sanitarias por las autoridades respectivas, "este Consulado General ha creído de

18 Véase la nota s. n., Shanghai 23 de noviembre de 1937 (p. 1).

19 Carlos Rodríguez Jiménez, nació el 21 de agosto de 1899 en la villa de Upata, estado Bolívar. Farmaceuta (1921). Doctor en Ciencias Políticas y Abogado (1924). Sobre su desempeño como Cónsul General en Tokio y los inicios de las relaciones diplomáticas entre Venezuela y Japón, véase: Molina Medina, 2012.

20 Véase la nota s. n., Tokio 27 de noviembre de 1937 (p. 1). 
urgente conveniencia exigir, además de los documentos aduaneros que deben cubrir cada despacho, una constancia de que el Capitán del buque ha recibido las cajas o fardos debidamente fumigados ... ”, a fin de que fueran evitadas con ello, la propagación de enfermedades endémicas. Así Ferrer hacía del conocimiento a los embarcadores de mercancías que el Gobierno de Venezuela se reservaba el derecho de tomar las acciones que juzgara conveniente sobre mercaderías provenientes de puertos asiáticos, para resguardar la salubridad nacional. Entre las medidas adoptadas se mencionan: a) Vacunación anticolérica obligatoria de todos los pasajeros; b) Desinfección del agua del buque destinada al consumo humano; y c) Desinfección de todos los alimentos que deban ser consumidos crudos, o sin suficiente cocción. (AHMPPRE 1937, Administración y Servicio Consular (China), Expediente $\left.\mathrm{N}^{\circ} 3\right){ }^{21}$

A mediados de diciembre insistió de nuevo ante el Ministro Gil Borges planteando el futuro de la jurisdicción consular de Venezuela en China, frente al desenvolvimiento de las hostilidades, la ocupación de Nanjing, Shanghai y la dominación japonesa del norte del país; pero ya no demandando el traslado provisional sino la ampliación de la jurisdicción consular a la colonia británica de Hong Kong, “a fin de, ante cualquier eventualidad, poder trasladarse a dicho puerto y ejercer legalmente su cargo ..." (AHMPPRE 1937, Política (China), Expediente $\left.\mathrm{N}^{\circ} 345\right){ }^{22}$

El Cónsul Ferrer señaló además del panorama descrito, la posibilidad de que los japoneses consolidaran un gobierno autónomo en Manchuria, todo lo cual haría que los representantes extranjeros ante el Gobierno chino, cesaran automáticamente sus funciones, pues no creía que ningún país así tuviera intereses e iba a aceptar la "autonomía” del "Estado" que impondría el Japón. Ante ese escenario, y que varios países, entre ellos Venezuela, no tuvieran derechos extraterritoriales en Shanghai, un gobierno de imposición militar sería la realidad más inmediata, lo que supondría la tolerancia o aceptación a semejante situación (AHMPPRE 1937, Política (China), Expediente $\mathrm{N}^{\circ}$ 345).

A inicios de 1938, Shanghai pareció presentar un clima de menor tensión. El 11 de enero se informó a Caracas sobre la nueva sede de la oficina consular (AHMPPRE 1938, Consulados (China), Expediente s. n.), ${ }^{23}$ además de pedir que se reanudara el envío de toda clase de correspondencia directamente a esa ciudad, ya que las comunicaciones de ese puerto con el exterior iban cobrando su normalidad, pues la

\footnotetext{
21 Véanse las notas $\mathrm{N}^{\circ} 78$, Shanghai 1 de diciembre de 1937 (p. 1) y nota verbal $\mathrm{N}^{\circ} 399$, Caracas 15 de enero de 1938 (p. 1).

22 Véase la nota $\mathrm{N}^{\circ} 81$, Shanghai 14 de diciembre de 1937 (p. 1).

23 La nueva sede el Consulado era: 40, Picardie Apartments (Avenue Petain), Shanghai. Véase la nota $\mathrm{N}^{\circ}$ 3, Shanghai 11 de enero de 1938 (p. 1).
} 
remesa de paquetes, cartas, entre otros, vía Manila, originaba retardos (AHMPPRE 1938, Consulados (China), Expediente $\mathrm{N}^{\circ} 2$ ). ${ }^{24}$ En torno a su gestión, lamentó que las hostilidades chino-japonesas hubiesen creado un momentáneo estado de desequilibrio haciendo impracticable toda gestión de entendimiento comercial y que, en tanto continuara ese panorama, todo esfuerzo vendría a ser inútil, no solo para el propósito de intercambio con nuevos mercados, sino para los grandes intereses económicos de países que mantenían antiguas relaciones con China, cuyas actividades se encontraban paralizadas. Sin embargo, desde Caracas, el 31 de enero de 1938, Arturo Uslar Pietri, encargado de la Dirección de Política Económica del Ministerio de Relaciones Exteriores, remitió el Boletín mensual $\mathrm{N}^{\circ} 1$ de datos económicos y financieros, con la finalidad de facilitarle a los agentes diplomáticos, consulares y comerciales, su labor de propaganda económica y financiera relativa a Venezuela, pero también con el compromiso de divulgar información relativa a China en nuestro país: "Como no se escapará a Usted, tal intercambio de noticias informativas entre los dos países incrementará, de seguro, sus relaciones comerciales”. (AHMPPRE 1937-1938, Consulados (China), Legajo No 3). ${ }^{25}$

Para Ferrer una vez instalado el Consulado en octubre de 1936, el estrecho intercambio con el Consulado General de Venezuela en Tokio había sido fundamental, trabajando en conjunto e intercambiando consultas. Daba cuenta asimismo sobre la comunicación verbal sostenida con la oficina del Ministerio de Relaciones Exteriores de China en Shanghai, desde mediados de diciembre de 1937, de donde se le sugirió fuera consultado la posibilidad de celebrar un Tratado de Amistad y Comercio, "el cual podría ser estudiado formalmente en Washington por la Embajada China y nuestra Legación, organismos capacitados para el caso" (AHMPPRE 1938, Consulados (China), Expediente s. n.). ${ }^{26}$

Sobre la situación política reinante, el 30 de marzo de 1938 se informó a Caracas sobre el manifiesto lanzado en Nanjing el 28 de marzo, en el que se anunciaba el establecimiento del “Gobierno Reformado de la República de China”, encabezado por Liang Hongzhi (梁鴻志) como presidente del Yuan Ejecutivo, el cual comprendía

24 Véase la nota $N^{\circ}$ 4, Shanghai 23 de enero de 1938 (p. 1).

25 Véase la nota $\mathrm{N}^{\circ} 329$, Caracas 31 de enero de 1938 (p. 1).

26 Subrayó los países que habían celebrado tratados comerciales con China: Gran Bretaña, EEUU, Bélgica, Brasil, Dinamarca, Francia, Italia, Japón, México, Holanda, Noruega, Perú, Portugal, España, Suecia, Chile, Suiza, Bolivia, Alemania, Austria, Finlandia, Grecia, Polonia, Checoslovaquia y Persia. Véase la nota $N^{\circ}$ 9, Shanghai 1 de febrero de 1938 (pp. 1-4). Sobre la situación general del Consulado, en marzo de 1938, le indicó a la Cancillería venezolana que la oficina consular carecía de muebles, máquinas de escribir, escritorios, archivadores, sillas, entre otros; y pide que “... ojalá fuera posible que ello se tuviera en cuenta para la próxima Ley de Presupuesto ... ”. Véase la nota $\mathrm{N}^{\circ} 18$, Shanghai 29 de marzo de 1938 (p. 1) (AHMPPRE 1937-1938, Consulados (China), Legajo № 3). 
en total a siete representantes de los poderes públicos, bajo los auspicios de las autoridades militares japonesas (AHMPPRE 1937, Política (China), Expediente $\left.\mathrm{N}^{\circ} 345\right) .{ }^{27}$ Por otro lado, la realidad de China en aquellos años hizo muy difícil el trabajo diplomático de promover el comercio con Venezuela, tal y como a cada momento lo notificaba el Cónsul General José Miguel Ferrer (AHMPPRE 1937-1938, Consulados (China), Legajo $\left.\mathrm{N}^{\circ} 3\right)^{28}$

\section{El ocaso de la sede consular venezolana}

Ante ese panorama, a finales de mayo de 1938, el Ministerio de Relaciones Exteriores venezolano informó al Cónsul Ferrer la decisión de eliminar de la Ley de Presupuesto General de Rentas y Gastos Públicos 1938-1939, a la oficina consular de Shanghai, sobre lo cual éste respondió: “... tengo el honor de informar a Usted que el próximo 3 de julio embarcaré, vía Europa, de regreso a Venezuela, pues los buques que cruzan el Pacífico tocan ahora solamente en los puertos del sur de China”, señalando además que llevaría con él, el archivo, sello, escudo y demás útiles del Consulado (AHMPPRE 1937-1938, Consulados (China), Legajo $\mathrm{N}^{\circ} 3$ ). ${ }^{29}$ Hasta el momento el clima político del país no parecía dar síntomas de cambio; el propio Ferrer con base a información oficial del Gobierno nacional de China, subrayó la preponderancia comercial japonesa en las áreas del norte y centro del país, militarmente ocupado, reflejando una idea sobre los intereses de Europa y América Latina en China, "hondamente afectados por las consecuencias del actual conflicto" (AHMPPRE 1937-1938, Consulados (China), Legajo $\mathrm{N}^{\circ} 3$ ). ${ }^{30}$

La clausura del Consulado General de Venezuela en Shanghai estuvo prevista para el 30 de junio. José Miguel Ferrer insistió a la Cancillería sobre la conveniencia para nuestra industria del establecimiento de al menos una agencia de productos nacionales, dado el interés por negociar que tenían algunos comerciantes. En esa misma fecha, se despidió de Franklin Esquire, presidente del Consejo Municipal de Shanghai, agradeciendo la cortesía y cooperación que le fue concedida durante sus servicios, pero además le explicó las instrucciones del Gobierno venezolano de

27 Véase la nota $\mathrm{N}^{\circ}$ 19, Shanghai 30 de marzo de 1938 (p. 1 y manifiesto completo, pp. 1-2).

28 El 29 de abril y el 28 de mayo de 1938 el Cónsul Ferrer remitió a la Cancillería venezolana los informes económico y comercial de China correspondiente a los meses de marzo y abril respectivamente, en donde puede apreciarse la complejidad de las dificultades que estaba viviendo el país asiático en aquel año: paralización del comercio exterior y derrumbe de la moneda nacional, entre otros aspectos. Véanse las notas Nㅜ 34, Shanghai 29 de abril de 1938 (p. 1; Informe Económico y Comercial, pp. 2-5); y nota $\mathrm{N}^{\circ} 38$, Shanghai 28 de mayo de 1938 (p. 1).

29 Véase la nota $\mathrm{N}^{\circ} 37$, Shanghai 25 de mayo de 1938 (p. 1).

30 Véase la nota $\mathrm{N}^{\circ} 39$, Shanghai 2 de junio de 1938 (pp. 1-2). 
cerrar temporalmente el Consulado en esa ciudad, ya no a partir del 30 de junio, sino del 5 de julio (AHMPPRE 1937-1938, Consulados (China), Legajo No 3). ${ }^{31}$

En efecto, tal y como lo anunció, ese día cerró la oficina consular venezolana en la ciudad de Shanghai, como puede conocerse en la que quizás sea la última comunicación que Ferrer expidió: “... con motivo del aniversario de nuestra independencia y la clausura de esta oficina consular, el periódico 'The China Press' ha publicado un retrato del Señor Presidente de la República, evocando a la vez detalles de la historia de Venezuela" (AHMPPRE 1937-1938, Consulados (China), Legajo $\mathrm{N}^{\circ}$ 3). ${ }^{32}$ De esta manera, se daba fin a casi dos años de esta inédita experiencia diplomática que el poeta caraqueño vivió y experimentó en China, pero también a los primeros contactos con el país asiático que, por iniciativa de Venezuela y sin ninguna reciprocidad hasta entonces por parte del Gobierno chino, sentó los primeros antecedentes de las relaciones Venezuela-China, las cuales habrían de formalizarse en 1943.

\section{Conclusiones}

Luego de la revisión documental realizada podemos indicar que al menos desde 1929 se dieron algunas iniciativas de particulares que se ofrecieron como posibles candidatos a Cónsul de los Estados Unidos de Venezuela en territorios chinos como Hong Kong, para el momento bajo dominio inglés. Sin embargo, no fue hasta el año 1936 cuando el Gobierno del presidente Eleazar López Contreras (1935-1941) acordó la creación del Consulado General de Shanghai, para el que fue designado el poeta y escritor José Miguel Ferrer.

Desde octubre de 1936 hasta el 5 de julio de 1938 funcionó esta sede en la mencionada ciudad China. La invasión japonesa iniciada en 1937 vendría a dificultar la misión encargada al escritor caraqueño. En repetidas ocasiones, el diplomático se dirigió a la Cancillería venezolana para dar cuenta de las penurias vividas en una ciudad bajo asedio nipón. Carencia de servicios públicos y movilidad, además del temor por su propia vida - debiendo marcharse momentáneamente a Manila, Filipinas -, son apenas menciones de un ambiente estático y de incertidumbre que no permitió, como tantas veces insistió, hacer las gestiones necesarias para lograr avances en el intercambio comercial.

Paralización de las actividades económicas, derrumbe de la moneda nacional, precarias condiciones sanitarias en las mercancías para exportar, así como en el

31 Véanse las notas $\mathrm{N}^{\circ}$ 41, Shanghai 6 de junio de 1938 (pp. 1-2); y nota s. n., Shanghai 30 de junio de 1938 (p. 1).

32 Véase la nota $\mathrm{N}^{\circ}$ 47, Shanghai 5 de julio de 1938 (p. 1). 
momento más delicado, la inexistencia prácticamente de autoridades chinas en Shanghai, fueron notificadas de manera oportuna por el representante del Gobierno venezolano. El entorpecimiento de sus funciones llevó a Ferrer a proponer el traslado y posteriormente ampliación de la jurisdicción del Consulado a Hong Kong, de lo cual no recibió respuesta afirmativa. En su afán por mejores resultados, mantuvo una comunicación permanente de consulta con el también Cónsul General de Venezuela en Tokio, Carlos Rodríguez Jiménez, quienes fueron partidarios de la pertinencia de que Caracas acreditara diplomáticos de mayor rango tanto en China como en Japón, lo que debió esperar unos años más.

El 5 de julio de 1938, día de la independencia venezolana, fue clausurado por José Miguel Ferrer el Consulado General de Venezuela en Shanghai, y con ello, se cerró un primer capítulo en el acercamiento diplomático con China que habría de reiniciarse en abril de 1943, cuando Li Dijun presentó sus Cartas Credenciales al presidente Isaías Medina Angarita (1941-1945), que lo acreditaron como Enviado Extraordinario y Ministro Plenipotenciario de China en Venezuela. A partir de entonces, instalada la Legación de su país en Caracas, se dio formalmente inicio a las relaciones diplomáticas bilaterales.

\section{Referencias}

Acerca de las medidas sanitarias que deben observarse al hacer despachos de mercancías procedentes de China. (1937). AHMPPRE: Administración y Servicio Consular (China).

Caracas: Expediente № 3.

Acerca del envío de la correspondencia al Consulado en Shanghai. (1938). AHMPPRE: Consulados (China). Caracas: Expediente № 2.

Anguiano Roch, E. (2010). De la Dinastía Qing en el siglo XIX hasta el fin de la República de China. In F. Botton Beja (Coord.), Historia Mínima de China (pp. 232-243). México D. F.: El Colegio de México.

Centro de Investigaciones Literarias. (Ed.) (1974). Ferrer, José Miguel (1903-1969). En Diccionario General de la Literatura Venezolana (1974). Mérida-Venezuela: Universidad de Los Andes.

Consulado General de Venezuela en Shanghai. Ingreso de Venezuela a la Corporación Consular de Shanghai. (1936). AHMPPRE: Consulados (China). Caracas: Expediente № 1.

Cornejo Bustamante, R. (Comp.) (2006). China: Perspectivas sobre su cultura e historia. México D. F.: El Colegio de México - Centro de Estudios de Asia y África, tomo II.

Cornejo Bustamante, R. (1996). La revolución china en la historia. In B. J. D. Toledo (Coord.), Asia y África en la historia (pp. 335-351). México D. F.: Universidad Autónoma Metropolitana.

Correspondencia del Consulado en Shanghai. (1937). AHMPPRE: Consulados (China). Caracas: Expediente № 4.

Correspondencia del Consulado en Shanghai. (1937-1938). AHMPPRE: Consulados (China).

Caracas: Legajo № 3.

de Venezuela, C. A. H., \& Kong, H. (1929a). AHMPPRE: Consulados (China). Caracas: Expediente s. n. de Venezuela, C. A. H., \& Kong, H. (1929b). AHMPPRE: Consulados (China). Caracas: Expediente № 2. 
El Cónsul informa del traslado de la oficina de Shanghai. (1938). AHMPPRE: Consulados (China).

Caracas: Expediente s. n.

El Cónsul informa desde Manila el bombardeo de Shanghai. (1937). AHMPPRE: Consulados

(China). Caracas: Expediente № 2.

Informe anual del año 1937. (1937). AHMPPRE: Consulados (China). Caracas: Expediente s. $\mathrm{n}$.

Informe anual del año 1937. (1938). AHMPPRE: Consulados (China). Caracas: Expediente s. n.

Ministerio de Relaciones Exteriores. (1937). Libro Amarillo 1936. Caracas-Venezuela: Ministerio de Relaciones Exteriores.

Ministerio de Relaciones Exteriores. (1999). Libro Amarillo 1998. Caracas-Venezuela: Ministerio de Relaciones Exteriores.

Ministerio de Relaciones Interiores. (1936). Gaceta Oficial de los Estados Unidos de Venezuela № 19.019. Caracas-Venezuela: Año LXIV - Mes X.

Molina Medina, N. (2012). Historia de las relaciones diplomáticas Venezuela -Japón (1938-2008). Mérida-Venezuela: Ediciones de la Secretaría de la Universidad de Los Andes-Centro de Estudios de África, Asia y Diásporas Latinoamericanas y Caribeñas “Dr. José Manuel Briceño Monzillo".

Molina Medina, N. (2015). Venezuela y el reconocimiento de la República Popular China en la ONU. Anuario GRHIAL, 9(9), 20-46.

Molina Medina, N. (2016). Las relaciones diplomáticas Venezuela - China (1943-1974). Cuadernos sobre Relaciones Internacionales, Regionalismo y Desarrollo, 11(21), 67-91.

Nueva dirección de la oficina: 40, Picardie Apartments Avenue Petain. (1938). AHMPPRE:

Consulados (China). Caracas: Expediente s. $n$.

Ocupación de territorios chinos en Shanghai por las tropas japonesas. (1937). AHMPPRE: Política (China). Caracas: Expediente № 343.

Situación grave en Shanghai. (1937). AHMPPRE: Política (China). Caracas: Expediente № 345. Suspensión del tráfico de estupefacientes. (1937). AHMPPRE: Política (China). Caracas: Expediente № 342.

Venegas Filardo, P. (1990). 53 nombres de poetas venezolanos. Caracas-Venezuela: Ediciones La Casa de Bello.

\section{Bionote}

\section{Norbert Molina Medina}

Center for African and Asian Studies, University of Los Andes (ULA), Mérida, Venezuela norbertmolinamedina@gmail.com

Norbert Molina Medina, Historiador. Magíster en Historia de Venezuela y Candidato a Doctor en Estudios Políticos por la Universidad de Los Andes (ULA), Mérida - Venezuela. Profesor Agregado a Dedicación Exclusiva en el área Afroasiática (Historia de Asia), adscrita al Departamento de Historia Universal de la Escuela de Historia - Facultad de Humanidades y Educación (ULA). Investigador del Centro de Estudios de África, Asia y Diásporas Latinoamericanas y Caribeñas “Dr. José Manuel Briceño Monzillo” (CEAA). Secretario General de la Asociación Venezolana de Estudios sobre China (AVECH, 委内瑞拉中国研究会). Editor de Cuadernos de China (中国笔记), y 
de Cuadernos de Cultura China (中国文化笔记本). Editor Asociado de Humania del Sur. Revista de Estudios Latinoamericanos, Africanos y Asiáticos, adscrita al CEAA. Coordinador de la Sección Venezuela de la Asociación Latinoamericana de Estudios de Asia y África (ALADAA). Autor de varios estudios relacionados con la historia de Asia contemporánea y de las relaciones diplomáticas de Venezuela con los países afroasiáticos. 